\title{
PERANCANGAN MULTIMEDIA INTERAKTIF UNTUK KAMPANYE PENGHEMATAN ENERGI LISTRIK RUMAH TANGGA
}

\author{
Andi Dahroni, Eka Putra', dan Muhammad Fadli Pratama ${ }^{3}$ \\ 1,2,3 Jurusan Teknik Informatika STT PLN \\ E-mai : andidahroni@sttpln.ac.id
}

\begin{abstract}
The limited development of power plants in the last five years has an impact on electricity supply in several regions in Indonesia. If you want to continue to feel electricity in Indonesia, one of the things that electricity users in Indonesia must do now is to save electricity. Media and technology can now be used by the government to promote electricity saving. The multimedia design program of the campaign for electronic voting was designed and created which would later be expected to provide simple education for the community in wise electronic selection. Designing interactive multimedia programs using the MDLC design method. The results of this study can foster a sense of community awareness of the electrical energy used to use electricity carefully. It was proven by $86 \%$ of respondents saying that the existence of a game of interactive applications in the form of games could make the community think wiser and adaptive
\end{abstract}

Keywords: Save Electricity, Multimedia Interaktif, Game.

\begin{abstract}
ABSTRAK
Terbatasnya pembangunan pembangkit listrik dalam lima tahun terakhir berdampak pada pasokan listrik di beberapa daerah di Indonesia.Jika ingin tetap merasakan adanya listrik di Indonesia, maka salah satu yang harus di lakukan oleh pengguna listrik di Indonesia saat ini adalah menghemat energi listrik. Media dan teknologi saat ini dapat dimanfaatkan oleh pemerintah untuk mensosialisasikan penghematan energi listrik. Program perancangan multimedia kampanye untuk pemililihan elektronik ini dirancang dan dibuat yang nantinya diharapkan dapat memberikan edukasi sederhana untuk masyarakat dalam pemilihan elektronik secara bijak. Perancangan program multimedia interaktif menggunakan metode perancangan MDLC. Hasil dari penelitian ini dapat menumbuhkan rasa kepedulian masyarakat terhadap energi listrik yang digunakan agar menggunakan listrik secara cermat. Dibuktikan dengan $86 \%$ responden mengatakan dengan adanya kampanya aplikasi interaktif berupa game dapat membuat masyarakat befikir lebih bijak dan adaptif.
\end{abstract}

Kata kunci: Hemat Listrik, multimedia interaktif, game. 


\section{PENDAHULUAN}

Dengan pertumbuhan ekonomi dan pertambahan penduduk yang pesat, Indonesia membutuhkan energi yang sangat besar untuk pemenuhan energi penduduknya. Menurut situs metrotvnews.com krisis listrik nasional terjadi pada 2018. Terbatasnya pembangunan pembangkit listrik dalam lima tahun terakhir berdampak pada pasokan listrik di beberapa daerah di Indonesia (metrotvnews). Jika ingin tetap merasakan adanya listrik di Indonesia, maka salah satu yang harus dilakukan oleh pengguna listrik di Indonesia saat ini adalah menghemat energi listrik.

Menurut data penjualan tenaga listrik PLN yang dikeluarkan oleh Menteri ESDM, menunjukan bahwa jumlah pelanggan tahun 2015 mencapai 61.167 .980 pelanggan. Dibandingkan dengan tahun 2014 angka ini naik sebesar 3.674.746 pelanggan atau 6,39\%. Dari jumlah pelanggan seluruhnya, kelompok rumah tangga merupakan jumlah terbesar yaitu 56.605.260 pelanggan atau $92,54 \%$.

Dari data tersebut, sektor rumah tangga mempunyai peran besar dalam penggunaan pasokan energi listrik di Indonesia. Namun kesadaran dari pelanggan sektor rumah tangga akan penghematan energi listrik masih sangat kurang. Menurut Direktur Jenderal Energi Baru Terbarukan dan Konservasi Energi (EBTKE) gaya hidup tidak hemat disebabkan berbagai faktor, antara lain ketidakpedulian dan belum terganggunya masyarakat dengan besaran kewajiban yang harus dibayarkan untuk mendapatkan enegi listrik [1]. Menurut General Manager PLN Wilayah Babel Zulfarida Paluzi, kesadaran masyarakat akan hemat energi listrik perlu ditingkatkan melalui edukasi dan sosialisasi untuk menambah kepedulian dan pengetahuan masyarakat terhadap pentingnya penghematan listrik.[2]

Perkembangan teknologi saat ini membuat kehidupan tidak lepas dari media. Informasi yang dengan mudah dan cepat dapat diakses. Menurut dampak dari perkembangan media berpotensi untuk tumbuh dan berkembangnya masyarakat belajar sehingga dalam setiap kegiatan bebasis edukasi potensi media tidak mungkin diabaikan. Media dan teknologi saat ini dapat dimanfaatkan oleh pemerintah untuk mensosialisasikan penghematan energi listrik. Miarso menjelaskan bahwa pada Multimedia interaktif, peserta tidak hanya memperhatikan penyajian atau objek, tetapi dipaksa berinteraksi selama mengikuti proses edukasi. [3]

\section{METODE/PERANCANGAN PENELITIAN}

\subsection{Metode Penelitian}

Metode pada penelitian ini dapat dilihat pada Gambar 1 berikut ini.

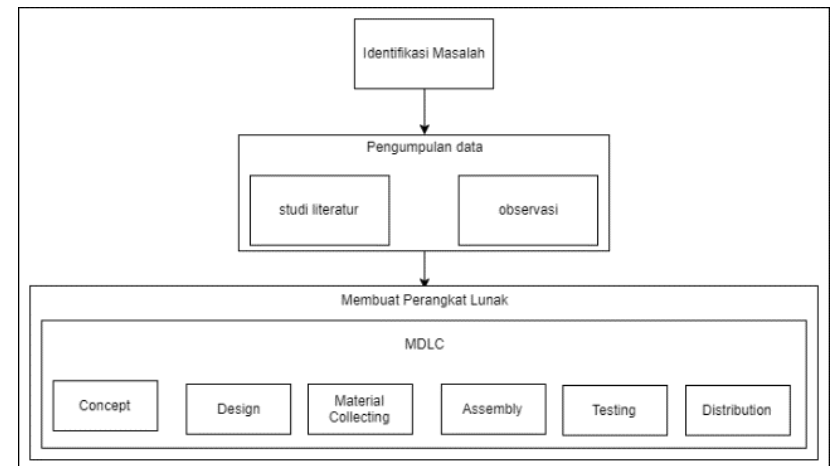

Gambar 1. Metodologi Penelitian

1. Identifikasi masalah

Pada tahapan identifikasi masalah ini dilakukan analisis-analisis terhadap masalah yang ada sehingga dapat terlihat kebutuhan apa saja yang di butuhkan. 
2. Pengumpulan data

Pada langkah pengumpulan data ini, berdasarkan hasil dari menentukan kebutuhan dilakukanlah beberapa cara dalam pengumpulan data yang bertujuan untuk memenuhi kebutuhan-kebutuhan. Beberapa cara dalam pengumpulan data ini yaitu, studi literature dan observasi

3. Membuat perangkat lunak

Penerapan hasil perancangan perangkat lunak yang telah dibuat dengan mempertimbangkan kemudahan dalam berinteraksi dengan perangkat lunak. Pada pembangunan aplikasi ini menggunakan metodologi MDLC.

MDLC (Multimedia Development Life Cycle). Multimedia Development Life Cycle menurut Luther MDLC memiliki 6 tahap, yaitu : tahap concept, tahap design, tahap material collecting, tahap assembly, tahap testing, dan tahap distribution. Tahapan tersebut dapat dijelaskan sebagai berikut seperti pada gambar 2. [4]

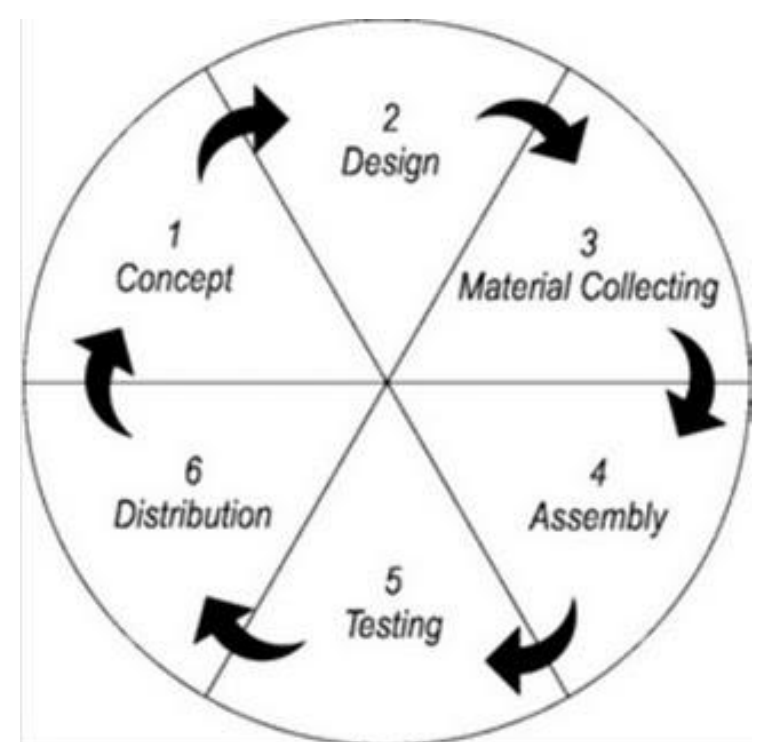

Gambar 2 Alur Multimedia Develompment Live Cycle

\subsection{Kerangka Penelitian}

Alur penelitian dari perancangan multimedia interaktif untuk kampanye penghematan energi listrik untuk rumah tangga, yaitu dapat dilihat pada Gambar 3. 


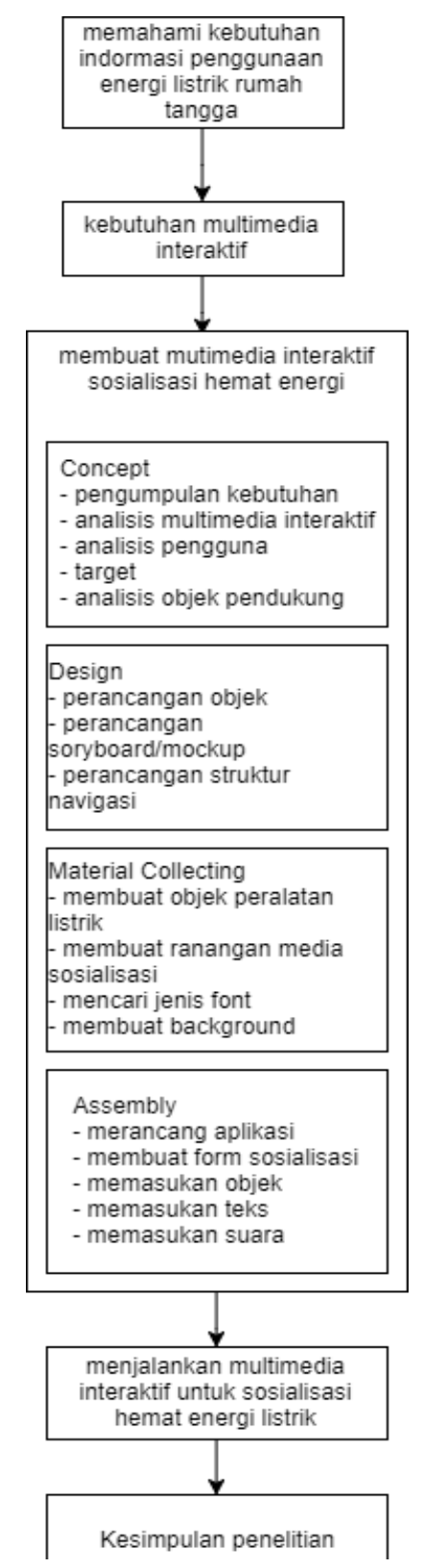

Gambar 3. Kerangka Penelitian

\section{HASIL DAN PEMBAHASAN}

Program perancangan multimedia kampanye untuk pemililihan elektronik ini dirancang dan dibuat yang nantinya diharapkan dapat memberikan edukasi sederhana untuk masyarakat dalam pemilihan elektronik secara bijak. Dengan begitu masyarakat pun dapat meminimalisir pengeluaran biaya listrik yang biasanya menurut kuesiner yang telah di bagikan tergolong mahal. Selain itu, dengan adanya kampanye ini dapat memberikan dampak yang sangat positif pada masyarakat pedalaman yang masih membutuhkan energi listrik yang banyak.

Aplikasi game ini dilengkapi dengan karakter yang lumayan menarik perhatian, karakter ini dapat di gerakkan melalui indicator tombol yang telah disediakan. Jadi secara tidak langsung game ini sudah memiliki ciri khas dan daya Tarik tersendiri sehingga minat edukasi melalui game masyarakat dapat lebih meningkat. 


\subsection{Multimedia Interaktif Game}

Game ini pada awalnya pengoperasiannya langsung ditampilkan halaman start up yang dihalaman ini memperlihatkan secara jelas logo dari STT-PLN dan nama dari game hemat listrik yang diberi singkatan "HeLi". Selain itu juga terlihat jelas indicator pengendali dari karakter game. User hanya tinggal ketuk layar untuk melanjutkan permainan.

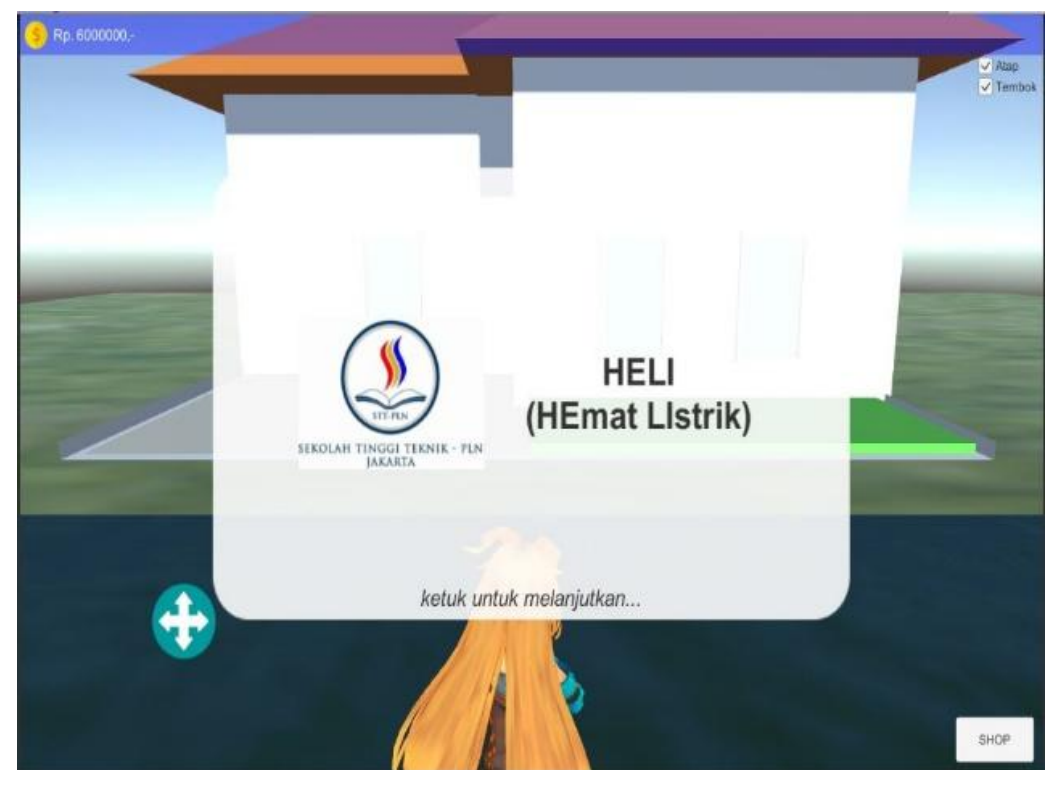

Gambar 4. Tampilan awal game

Gambar 4 menunjukan tampilan awal dari aplikasi multimedia interaktif untuk kampanye penghematan energi listrik untuk rumah tangga.

Game ini juga dilengkapi dengan menu Shop yang memudahkan user untuk membeli perabotan dan elektronik sesuai dengan kebutuhan dan sesuai dengan dana yang telah tersedia, dan pada contoh yang tersedia saat ini diberikan Rp.6.000.000

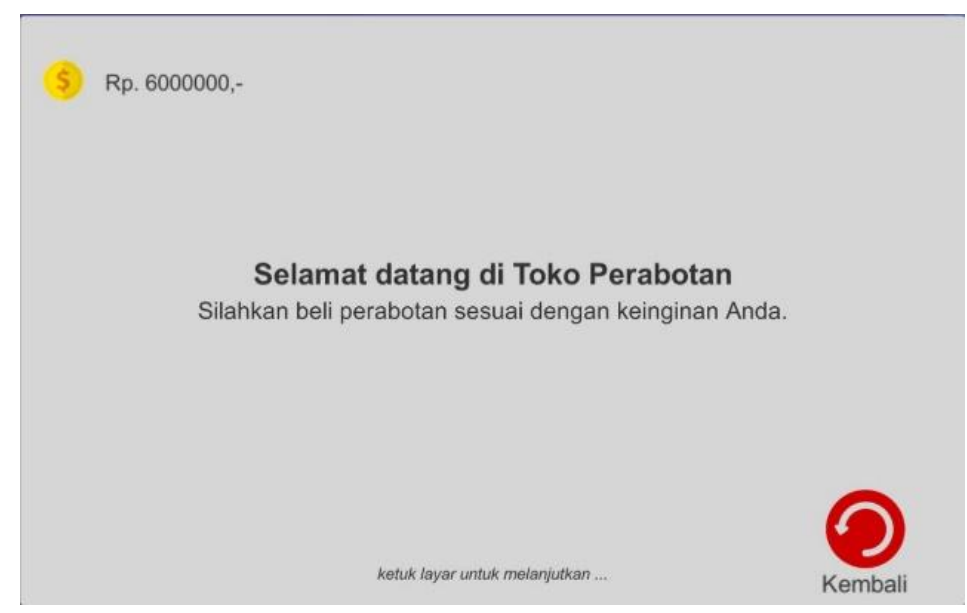

\section{Gambar 5 Tampilan Shop}

Gambar 5 menunjukan tampilan menu pembelian dari aplikasi multimedia interaktif untuk kampanye penghematan energi listrik untuk rumah tangga. Pada halaman shop ini terdapat juga tempat pembelian AC yang pada halaman tersebut dapat dipilih AC tipe apa saja yang ingin di beli, dan juga terdapat harga dari masing-masing jenis tipe AC yang ditunjukan pada gambar 6 . 


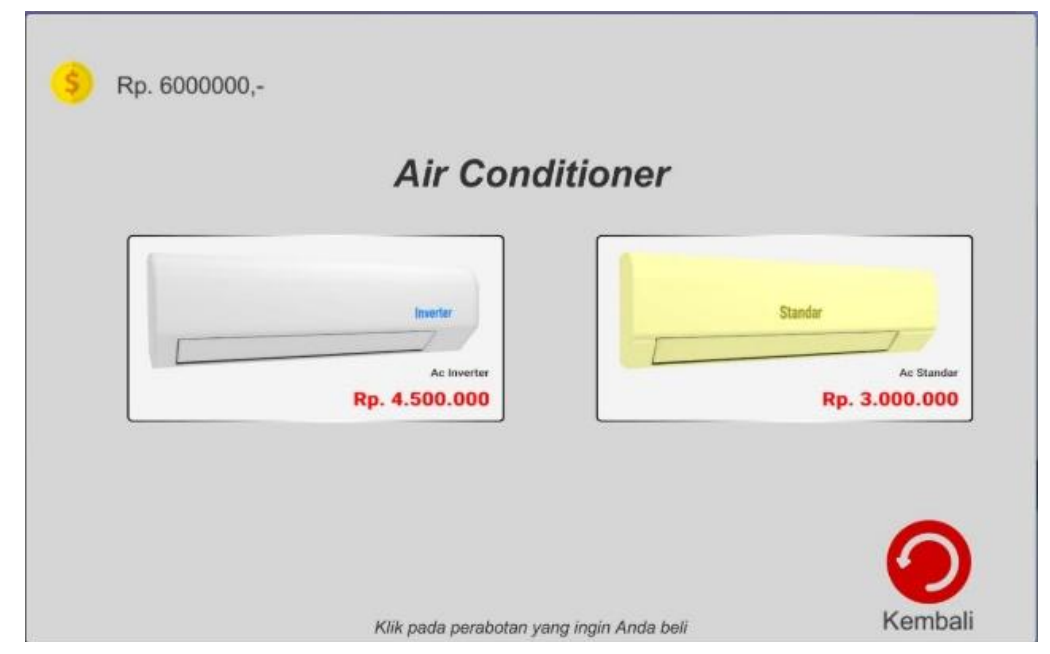

Gambar 6 Halaman pembelian AC

Setelah user di beri tugas untuk belanja elektronik sesuai dengan masing-masing jenis atau tipe yang diinginkan, maka pada halaman shop ini juga terdapat halaman yang memberikan perkiraan biaya yang akan di keluarkan perhari dan perbulan sesuai dengan jenis elektronik yang dipilih. Dari contoh game yang telah dimainkan, maka telah dipilih jenis AC yang Inverter, TV yang LED, dan Lampu yang LED, terlihat pada gambar 7.

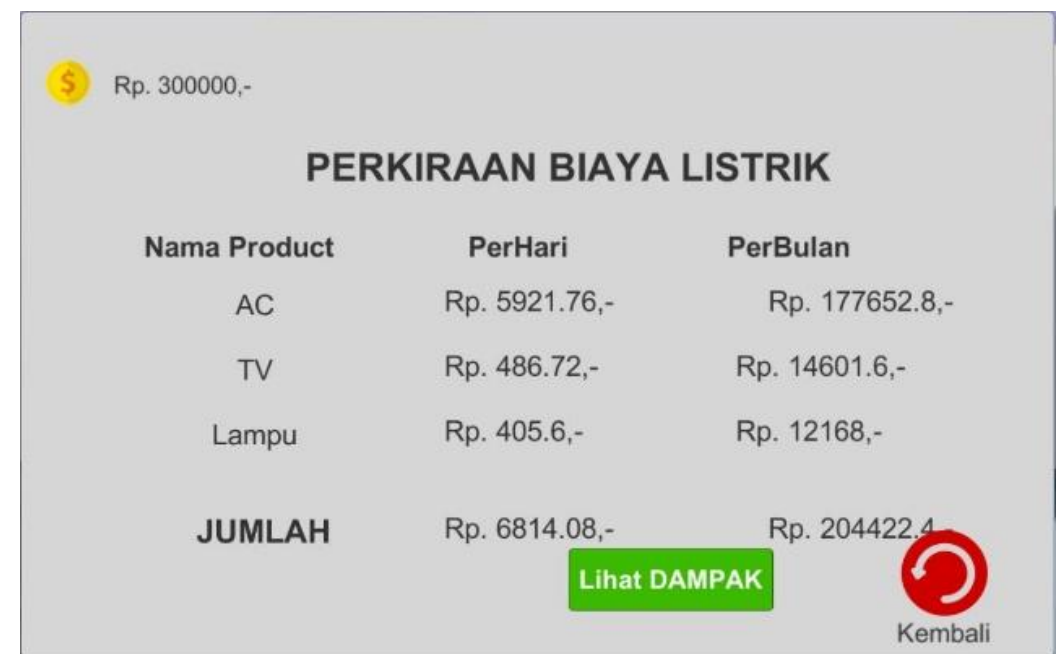

Gambar 7 Halaman biaya listrik

Setelah perkiraan biaya listrik dijumlahkan, system game akan secara otomatis menampilkan tombol dampak dari jenis elektronik yang telah dibeli tadinya.

\subsection{Hasil Kuesioner}

Untuk lebih mendapatkan informasi secara real, kami peneliti juga membuat beberapa pertanyaan yang disusun menjadi sebuah kuesioner yang nantinya akan ditujukan kepada masyarakat yang khususnya masyarakat pada era saat ini. Kuesioner ini dapat diisi secara online yang di share pada google doc yang link nya akan dibagikan oleh admin. Pada hasil ini terdapat 82 orang responden yang bersedia mengisi kuesioner.

Dari data kuesioner di dapat bahwa 72 persen responden menyatakan tidak adanya atau belum adanya sosialisasi mengenain pemilihan elektronik yang baik dan hemat energi seperti terlihat pada gambar 8 . 
Sejauh ini, adakah sosialisasi tentang pemilihan elektronik yang baik?

82 responses

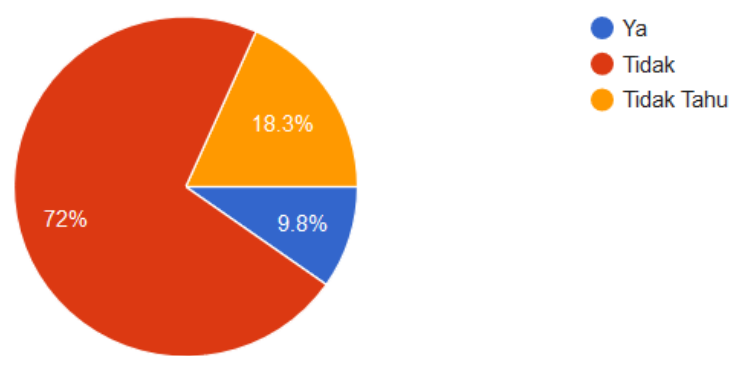

Gambar 8 Kuesioner 1

Pada data selanjutnya didapat data yaitu lebih dari $92 \%$ masyarakat mengatakan perlunya sosialisasi dalam pemilihan alat elektronik secara bijak dan baik sperti terlihat pada gambar 9 .

\section{Perlukah Anda mendapatkan sosialisasi untuk pemilihan alat elektronik} yang baik?

82 responses

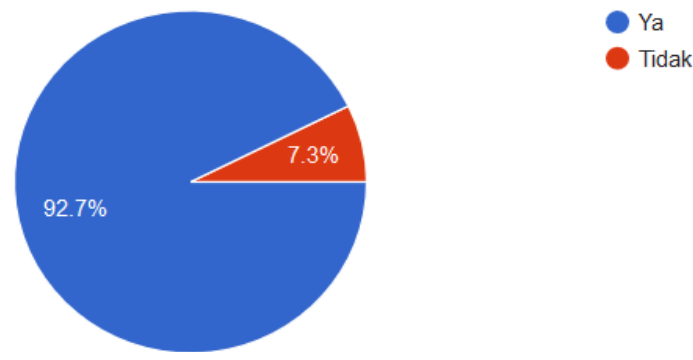

Gambar 9 Kuesioner 2

Lebih dari 97\% masyarakat mengatakan bahwa sosialisasi dalam pemilihan alat elektronik secara bijak dan baik sangat memberikan keuntungan bagi masyarakat itu sendiri seperti terlihat pada gambar 10 .

Setujukah Anda, jika sosialisasi mengenai listrik ini akan memberikan keuntungan untuk masyarakat yang belum paham?

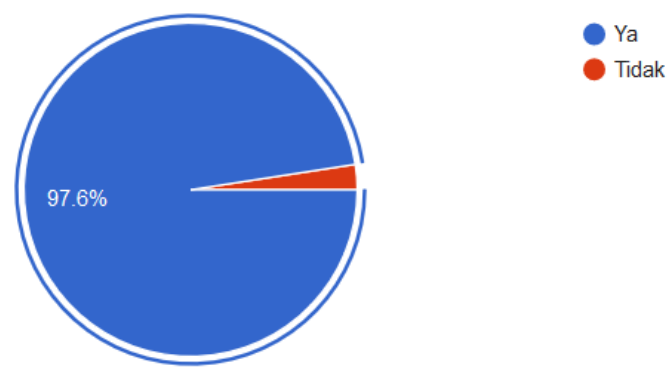

Gambar 10 Kuesioner 3 
Lebih dari $86 \%$ masyarakat mengatakan bahwa kampanye sosialisasi dalam bentuk game dapat membuat masyarakat berfikir lebih bijak dan adaptif seperti terlihat pada gambar 11.

Setujukah Anda jika metode kampanye ini dibuat dalam bentuk game agar dapat lebih adaptif?

82 responses

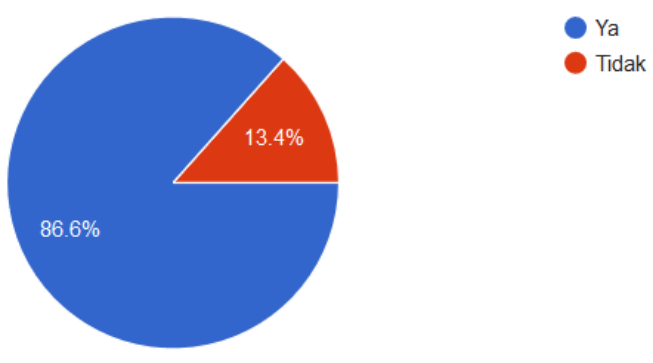

Gambar 11 Kuesioner 4

\section{KESIMPULAN DAN SARAN}

Penelitian ini dibuat dalam rangka membantu warga masyarakat mengenai sosialisasi hemat listrik dan pemilihan perangkat listrik yang baik di era saat ini. Dengan dibuatnya sebuah perangkat aplikasi multimedia interaktif berupa game, pengguna akan lebih mudah memahami informasi yang disampaikan. Hasil dari penelitian ini diharapkan akan dapat menumbuhkan rasa kepedulian masyarakat terhadap energi listrik yang digunakan agar menggunakan listrik secara cermat. Peneliti sangat berharap hasil penelitian ini sedikit banyaknya memberi manfaat khususnya bagi peneliti dan umumnya bagi semua masyarakat yang ada di Indonesia.

\section{UCAPAN TERIMAKASIH}

Penulis mengucapkan terima kasih kepada Instansi STT PLN yang telah memberi dukungan yang membantu pelaksanaan penelitian dan atau penulisan artikel.

\section{DAFTAR PUSTAKA}

[1] Ferial. (25 November 2015). "Jadikan Hemat Energi Sebagai Gaya Hidup." Retrieved from http://ebtke.esdm.go.id/post/2015/11/25/1027/jadikan.hemat.energi.sebagai.gaya.hidup

[2] Ismainy, V. E. (2015). Indonesia Terancam Krisis Listrik Pada 2018. Retrieved from http://ekonomi.metrotvnews.com/read/2015/02/04/353984/indonesia-terancam-krisis-listrikpada-2018

[3] Lia, Linda (2015). Multimedia Interaktif sebagai salah satu lternatif pembelajaran dalam bidang pendidikan sains.Universitas PGRI Palembang. Palembang

[4] Binanto, Iwan. (2010). Multimedia Dasar-Dasar Teori dan Pengembanyanya. Yogyakarta. Andi 